\title{
Does Technology Flow Matter for Regional Technological Specialization? Evidence from China
}

\author{
Feng-Chao LIU ${ }^{\mathrm{a}}$, Yuan LIN ${ }^{\mathrm{b},{ }^{*}}$ and Rong-Kang MA \\ Faculty of Management and Economics, Dalian University of Technology, Dalian 116024, China \\ afengchaoliu@126.com, ${ }^{b}$ dbzc@sina.com, marongkang@foxmail.com \\ ${ }^{*}$ Corresponding author
}

\begin{abstract}
Keywords: Region, Technological specialization, Technology flow, Knowledge spillover, Knowledge stock, Absorptive capacity.
\end{abstract}

\begin{abstract}
Based on patent database of the China State Intellectual Property Office, the study analyzes 75,458 transfer data of patent application rights and patent rights and 238,807 non-public data of patent citations, which are used as proxy variables of technology flow of market-based and non-market-based, respectively, among 30 provinces in China from 2009 to 2015. Random effect models of panel data results indicate that there are regional differences in the impact of technology flow on technological specialization. Under the conditions of market-based (rent spillovers), the technological specialization of regions with high technology knowledge stock are more positively affected by technology flow, but regions with low technology knowledge stock are not. While under the conditions of non-market-based (pure knowledge spillovers), there are not significant for both types of regions. Based on the findings of this study, policy implications are discussed.
\end{abstract}

\section{Introduction}

Technological specialization refers to those technologies with relative advantages which is numbers and position distribution of in all technology classifications or technology fields [1,2]. To a certain extent, technological specialization reflects the knowledge creation ability, competence or core competitive advantage in a specific technological field of a country, region or firm [2-6]. Hence, the research on the realization mechanism and innovative function of it has been continuously concerned by scholars of strategic management and technological innovation $[4,5,7,8]$.

There are three important perspectives on the study of the influencing factors of technological specialization. First, research from the perspective of market demand and intermediate service support $[2,9,10]$. Second, research from the perspective of macro environment, such as national innovation system and comparative institutional advantages of a country, etc.[5,8,11]. Third, research from the perspective of the micro carrier role [3,5,12]. Though the effect of technological specialization on countries' technological profile and firms' innovation has recently been highlighted in the extant literature, the empirical research on the factors that affect technological specialization at regional level are still limited.

This study fills the voids by developing a new important perspective on above by using the statistical data of the transfer of patent application rights and the transfer of patent rights from China State Intellectual Property Office (SIPO). We focus on the effect of technology flow on technological specialization at the regional level. There are three reasons for this. First, in the context of globalization, most of the interaction of innovative activities occurs at the regional level within a country [13,14], especially typical for China. Second, with the facilitation of transportation and information technology, the free mobility of technology resources is increasingly strengthened, which might, to some extent, affect regional technological specialization. Third, the technological specialization may lead to the formation of regional division of innovative labor [15], which means a region might focus on its comparative advantage fields of technology, but purchases peripheral technologies from specialized market in other regions. The results will benefit all parties, promote the effective use of resources and increase the overall social welfare of the society $[16,17]$. 
In this study, we will unravel the impact of technology flow on technological specialization of different types of regions within a country, which are not mentioned in previous research. We take China as a sample, because there are huge disparities exist in Chinese provinces in terms of natural endowments, economic, social, and technological development, and innovation capabilities $[18,19]$. Thus, the great differences of technology flow and specialization in different types of regions are helpful to unravel the relationship between them.

The study is divided into four sections. The next section explains the statistical methodology adopted. Section 3 reports the results of the regressions and Section 4 closes with some general considerations for technological policy.

\section{Data and Variables}

\section{Data}

The statistical and econometric analysis of this study is based on the use of patent application statistics as a proxy for the underlying pattern of technological activities of regions and we take 30 provincial administrative units within China as regional boundary. Patent statistics have been shown that they can be useful indicators of technological activities in many works [8,20,21]. The patent application statistics are derived from the patent database of the China State Intellectual Property Office (SIPO). According to IPC8 -Technology Concordance published by the World Intellectual Property Organization (WIPO) [1], we assigned the 4 bits IPC main classification code of patent applications for inventions of each province to 35 sector technology field. After classification and addition, the quantitative distribution of patents in 30 provinces in 35 sector technology fields is obtained and can be used to measure technological specialization of regions.

The measurement of technology flow in our study is also derived from the statistical data of the transfer of patent rights in the patent databases of SIPO, including the transfer of patent application rights and the transfer of patent rights. With the transfer of the patent right, the name and address information of the patent owner will be changed, which will be recorded in the legal status information on the patent database of SIPO. By retrieving the address change information of the patented (application) right holder, a total of 75,458 patent transfer data for 30 provinces of China was retrieved from 2009 to 2015 . We also get 238,807 non-public data of patent citations from SIPO. We exclude the data of the local patent transfers. Additionally, the other supporting data on China's macro-economy was collected from China Statistical Yearbook and Chinese Scientific and technological Statistics Yearbook.

Before this study is carried out, we will distinguish the different types of regions according to their stock of the technology knowledge, which reflects the technological innovation potential [22] and absorptive capacity [23]. We divide two types of regions according to the number of valid patents owned by each province being more than 90000 pieces until 2015, we get 15 provinces as regions with high stock of technology knowledge (H-Region), including Beijing, Shanghai, Jiangsu, Zhejiang, Guangdong, Shandong, Anhui, Sichuan, Fujian, Henan, Hubei, Hunan, Tianjin, Liaoning and Chongqing. There are a total number of valid patents are 3,500,389 items in the 15 provinces, which account for $89.35 \%$ of the whole country. The other 15 provinces as regions with low stock of technology knowledge (L-Region), including Hebei, Shanxi, Inner Mongolia, Jilin, Heilongjiang, Jiangxi, Guangxi, Hainan, Guizhou, Yunnan, Shaanxi, Gansu, Qinghai, Ningxia and Xinjiang, which the number of valid patents only accounts for $10.65 \%$ of the total.

\section{Dependent Variable}

Technological specialization. Following previous studies $[4,5,11]$, we use the coefficient of variation $(C V)$ of the revealed technological advantage $(R T A)$ to be a measure of technological specialization of a region. The $R T A$ index of a region in a particular technological sector is given by the regional share of patenting in that particular sector divided by its national share of total patenting in all sectors. The formula for the calculation of $R T A$ is as follows,

$$
R T A=\left(P_{i j} / \sum_{i} P_{i j}\right) /\left(\sum_{j} P_{i j} / \sum_{i} \sum_{j} P_{i j}\right)
$$


where $P_{i j}$ is the number of patents of region $i$ in sector $j$. The formula shows that the $R T A$ index of region $i$ in a particular technological sector $j$ is given by the national share of patenting in that particular sector divided by the national share of patenting in all sectors. The index varies around 1. A value above 1 shows the region with a comparative technological advantage in a particular sector (i.e. technological specialization), while a value below 1 shows the region with a comparative technological disadvantage (i.e. technological de-specialization).

Based on the RTA index of technological advantage the coefficient of variation $(C V)$ of the $R T A$ is a measure of technological specialization of the region $i$,

$$
C V_{i}=\frac{\sqrt{\operatorname{Var}\left(R T A_{i}\right)}}{\operatorname{Mean}\left(R T A_{i}\right)}
$$

A high $C V_{i}$ indicates that the region $i$ concentrates its competencies in narrow areas or niches, whereas a low $C V_{i}$ points towards regions $i$ spreading out their competencies across a larger canvas of technologies.

\section{Independent Variables}

Technology Flow. Technology flow is one of the important mechanisms of knowledge spillovers. Griliches (1992) distinguished knowledge spillovers into rent spillovers and pure knowledge spillovers. Rent spillovers are market-based knowledge spillovers, while pure knowledge spillovers are non-market-based spillovers [22]. As there are two directions in regional technology flow, which includes outward and inward flow, we take the regional patent selling (SELL) and cited patent (CITED) as the proxy indicators of technological outward flow of market-based and non-market-based respectively. Similarly, we also use the regional patent buying $(B U Y)$ and patent cites $(C I T E D)$ as the proxy indicators of technological inward flow of market-based and non-market-based respectively.

\section{Controlled Variables}

The control variables are variables that are not the focus of this study, but may affect the results of this study. According to the existing literature $[2,5,7,24]$, we include regions' $R \& D$ investment $(R D)$ and region' foreign direct investment $(F D I)$ as control variables, in order to control the effect of both variables on regional technology progress, and use GDP deflator to eliminate the effect of price factors.

\section{Results}

Table 1 provides the results of all estimated random effect models of panel data. Model 1 Model 4 are the estimated results of H-Region, while Model $5 \sim$ Model 8 are the results of L-Region.

In Model 1 and Model 5, under the conditions of market-based (rent spillovers), we can see that there are significant positive effect of the technological outward flows on regional technological specialization in H-Regions, but not in L-Regions. The same results also appear in Model 3 and Model 7 when the technologies of region inward flows. The results of above indicating that there is more significant direct effect of technology flow on regional technological specialization in H-Regions than L-Regions in terms of market transactions.

While under the conditions of non-market-based (pure knowledge spillovers), the coefficients of CITED in both Model 2 and Model 4, as well as the coefficients of CIT in both Model 6 and Model 8 are all not significant in two types of region. These results indicate that there are no significant effect of the technology flow on regional technological specialization in H-Regions and L-Regions in terms of non-market transactions. 
Table 1 Results of model regression

\begin{tabular}{|c|c|c|c|c|c|c|c|c|}
\hline \multirow{2}{*}{ Variables } & \multicolumn{4}{|c|}{ H-Region } & \multicolumn{4}{|c|}{ L-Region } \\
\hline & Model 1 & Model 2 & Model 3 & Model 4 & Model 5 & Model 6 & Model 7 & Model 8 \\
\hline \multirow[t]{2}{*}{$\ln R D$} & 0.073 & $0.297 * *$ & -0.016 & $0.347 * *$ & $-0.253 * * *$ & $-0.205 * * *$ & $-0.297 * * *$ & $-0.246^{* * *}$ \\
\hline & $(0.176)$ & $(0.151)$ & $(0.166)$ & $(0.139)$ & $(0.063)$ & $(0.072)$ & $(0.058)$ & $(0.058)$ \\
\hline \multirow[t]{2}{*}{$\ln F D I$} & $-0.178^{*}$ & $-0.248 * *$ & $-0.207 * *$ & $-0.249 * * *$ & 0.040 & 0.045 & 0.031 & 0.054 \\
\hline & (0.098) & $(0.097)$ & $(0.095)$ & $(0.096)$ & $(0.054)$ & (0.054) & (0.056) & $(0.057)$ \\
\hline \multirow[t]{2}{*}{$\ln S E L L$} & $0.137 * *$ & & & & -0.012 & & & \\
\hline & $(0.056)$ & & & & $(0.027)$ & & & \\
\hline \multirow[t]{2}{*}{$\ln C I T E D$} & & 0.078 & & & & -0.064 & & \\
\hline & & $(0.072)$ & & & & $(0.051)$ & & \\
\hline \multirow[t]{2}{*}{$\ln B U Y$} & & & $0.240 * * *$ & & & & 0.037 & \\
\hline & & & (0.069) & & & & $(0.033)$ & \\
\hline \multirow[t]{2}{*}{$\ln C I T$} & & & & 0.044 & & & & -0.030 \\
\hline & & & & $(0.071)$ & & & & $(0.034)$ \\
\hline \multirow[t]{2}{*}{ Constant } & -0.938 & $-3.219 * *$ & 0.195 & $-3.691 * * *$ & $2.237 * * *$ & $1.881 * * *$ & $2.715 * * *$ & $2.124 * * *$ \\
\hline & (1.783) & (1.511) & (1.740) & (1.399) & $(0.675)$ & $(0.685)$ & $(0.622)$ & $(0.639)$ \\
\hline Wald $\chi^{2}$ & 19.900 & 13.950 & 28.180 & 12.760 & 43.910 & 46.950 & 43.480 & 43.770 \\
\hline Prob $>\chi^{2}$ & 0.000 & 0.003 & 0.000 & 0.005 & 0.000 & 0.000 & 0.000 & 0.000 \\
\hline Obs. & 60 & 60 & 60 & 60 & 60 & 60 & 60 & 60 \\
\hline No. of Prov. & 15 & 15 & 15 & 15 & 15 & 15 & 15 & 15 \\
\hline
\end{tabular}

Note: Figures within parentheses are robust standard errors. $* * * p<0.01 . * * p<0.05 . * p<0.1$. H-Region $=$ region with high stock of technology knowledge; L-Region = region with low stock of technology knowledge

\section{Conclusion and Discussion}

In the context of globalization, how does the free flow of technologies and knowledge affect regional specialization? This study empirically investigates the effects of technology flow on technological specialization at regional level. An econometric analysis based on panel data of 30 Chinese provinces from 2009 to 2015 suggests, under the conditions of market-based (rent spillovers), there is a statistically significant positive effect on the relationship between technology flow and technological specialization for H-Regions, but L-Regions not significant. While under the conditions of non-market-based (pure knowledge spillovers), not significant for both types of region.

The purpose of different external technology sourcing strategies is to get access to technologies that are embedded in other acts [25]. In this process, absorptive capacity is undoubtedly the most important [23]. The stock of regional technological knowledge reflects the state of knowledge production, the potential of technological innovation [22] and the absorptive capacity [23] to new technological knowledge. With much stronger absorptive capacity and recombination of knowledge in technological innovation [26], it becomes easier for H-regions to strengthen their specialization and competence than L-regions. But for the absorption and transformation of pure knowledge spillovers, the results might be more indirect. That is, the overflow knowledge and existing knowledge elements has to go through the process of reorganizing [26,27], before it could be applied to technological development practice. Therefore, pure knowledge spillovers might do not have direct effects as rent spillovers.

What we find may be interesting and valuable for policy makers. Firstly, we suggest central government attaches great importance to the specialization of regional technology, which will fertilize regional comparative technological advantages and regional division of innovative labor, optimize the 
allocation of R\&D resources and reducing waste. Secondly, governments should increase policy support to enlarge technological market transactions, and thirdly, in the meantime, increase technology accumulation of L-Regions, which can help them improve the absorptive capacity. The main policies are still to increase the policy guidance and incentives for R\&D investment by firms in the region.

We acknowledge this study has some limitations. Currently, only a limited number of empirical studies analyzed technological transaction, due to the lack of comprehensive data sets and to the scarcity of information on the contractual terms of such transaction [28], so we have to use patent transaction as a proxy of technological transaction. But patent transaction might not capture all information of technological transaction. We believe that if data conditions were improved, more interesting topic related to this paper would be discussed in future research.

\section{Acknowledgement}

This research was financially supported by the National Natural Science Foundation of China (NNSFC, grant No.71602017, No.71673037, No.71473026) and the Humanities and Social Science Youth Foundation of Ministry of Education of China (grant No.15YJC630092).

\section{References}

[1] Schmoch U, Laville F, Patel P, Frietsch R. Linking Technology Areas to Industrial Sectors. Final Report to the European Commission, DG Research, 2003.

[2] Vertova G. Stability In National Patterns Of Technological Specialisation:Some Historical Evidence From Patent Data. Economics of Innovation \& New Technology. 1999;8; 331-354.

[3] Kim J, Lee C, Cho Y. Technological diversification, core-technology competence, and firm growth. Research Policy. 2016;45; 113-124.

[4] Cantwell J, Vertova G. Historical evolution of technological diversification. Research Policy. 2004;33; 511-529.

[5] Urraca-Ruiz A, Laguna-Molina NE. Dynamic technological specialization, aggregated convergence and growth. International Economics and Economic Policy. 2016;13; 1-27.

[6] Archibugi D, Pianta M. Specialization and size of technological activities in industrial countries: The analysis of patent data. Research Policy. 1992;21; 79-93.

[7] Meelen T, Herrmann AM, Faber J. Disentangling patterns of economic, technological and innovative specialization of Western economies: An assessment of the Varieties-of-Capitalism theory on comparative institutional advantages. Research Policy. 2017;46; 667-677.

[8] Abdel-Rahman HM. When do cities specialize in production? Regional Science \& Urban Economics. 1996;26; 1-22.

[9] Archibugi D, Pianta M. Specialization and size of technological activities in industrial countries: The analysis of patent data. Research Policy. 1992;21; 79-93.

[10] Vertova G. National technological specialisation and the highest technological opportunities historically. TECHNOVATION. 2001;21; 605-612.

[11] Cantwell J, Piscitello L. Accumulating technological competence: its changing impact on corporate diversification and internationalization. Industrial \& Corporate Change. 2000;9; 21-51.

[12]Chung S. Building a national innovation system through regional innovation systems. TECHNOVATION. 2002;22; 485-491.

[13] Cooke P, Uranga MG, Etxebarria G. Regional innovation systems: Institutional and organisational dimensions. Research Policy. 1997;26; 475-491. 
[14] Arora A, Gambardella A. The changing technology of technological change: general and abstract knowledge and the division of innovative labour. Research Policy. 1994;23; 523-532.

[15] Arora A, Gambardella A. Ideas for rent: an overview of markets for technology. Industrial \& Corporate Change. 2010;19; 775-803.

[16] Arora A, Cohen WM, Walsh JP. The acquisition and commercialization of invention in American manufacturing: Incidence and impact. Research Policy. 2016;45; 1113-1128.

[17]Hong W, Su YS. The effect of institutional proximity in non-local university-industry collaborations: An analysis based on Chinese patent data. Research Policy. 2013;42; 454-464.

[18] Li X. Behind the recent surge of Chinese patenting: An institutional view. Research Policy. 2012;41; 236-249.

[19] Griliches Z. Issues in Assessing the Contribution of Research and Development to Productivity Growth. Bell Journal of Economics. 1979;10; 92-116.

[20] Pavitt K. R\&D, patenting and innovative activities : A statistical exploration. Research Policy. $1982 ; 11 ; 33-51$.

[21] Griliches Z. The Search for R\&D Spillovers. Scandinavian Journal of Economics. 1992;94; 29-47.

[22] Cohen WM, Levinthal DA. Absorptive Capacity: A New Perspective on Learning and Innovation. Administrative Science Quarterly. 1990;35; 39-67.

[23] Cantwell J, Piscitello L. Accumulating technological competence: its changing impact on corporate diversification and internationalization. Industrial \& Corporate Change. 2000;9; 21-51.

[24] Vareska VDV. Balancing your technology - sourcing portfolio: How sourcing mode diversity enhances innovative performance. Strategic Management Journal. 2013;34; 610-621.

[25] Fleming L. Recombinant Uncertainty in Technological Search. MANAGE SCI. 2001;47; 117-132.

[26] Guan JC, Yan Y. Technological proximity and recombinative innovation in the alternative energy field. Research Policy. 2016;45; 1460-1473.

[27] Caviggioli F, De Marco A, Scellato G, Ughetto E. Corporate strategies for technology acquisition: evidence from patent transactions. Management Decision. 2017; 55. 